\title{
DOSY Analysis of Micromolar Analytes: Resolving Dilute Mixtures by SABRE Hyperpolarization
}

\author{
Indrek Reile, Ruud L. E. G. Aspers, Jean-Max Tyburn, James G. Kempf, Martin C. Feiters, \\ Floris P. J. T. Rutjes, and Marco Tessari*
}

\begin{abstract}
DOSY is an NMR spectroscopy technique that resolves resonances according to the analytes' diffusion coefficients. It has found use in correlating NMR signals and estimating the number of components in mixtures. Applications of DOSY in dilute mixtures are, however, held back by excessively long measurement times. We demonstrate herein, how the enhanced NMR sensitivity provided by SABRE hyperpolarization allows DOSY analysis of low-micromolar mixtures, thus reducing the concentration requirements by at least 100-fold.
\end{abstract}

$N_{\text {MR spectroscopy is one of the most versatile analytical }}$ techniques for the study of molecules and mixtures. A multitude of NMR techniques have been devised to resolve, identify, and quantify analytes in increasingly complex samples. Among such methods, DOSY (diffusion ordered spectroscopy $)^{[1]}$ allows the discrimination of molecules in solution according to their rates of diffusion.

The indirect dimension of 2D DOSY plots displays diffusion coefficients of analytes, enables the correlation of signals from the same molecule, and the estimation of molecular sizes. Moreover, DOSY allows the correlation of signals that lack mutual coupling and, therefore, would be difficult to identify as originating from the same molecule by other NMR experiments. DOSY has been used to study natural mixtures ${ }^{[2]}$ and pharmaceutical preparations, ${ }^{[3]}$ in which it helps to assess the number and variety of species in solution.

Application of DOSY to mixture analysis requires minimal spectral overlap and a sufficiently high signal-tonoise ratio (typically SNR $>100$ ). While that criterion can, up to a point, be met by signal averaging, that would be too timeconsuming for DOSY of sub-millimolar mixtures. Regarding spectral overlap, that issue can be addressed by higherdimensional DOSY, such as $3 \mathrm{D}^{\left[{ }^{[4]}\right.}$ or pureshift-DOSY. ${ }^{[5]}$

[*] Dr. I. Reile, R. L. E. G. Aspers, Dr. M. C. Feiters, Prof. F. P. J. T. Rutjes, Dr. M. Tessari

Institute for Molecules and Materials, Radboud University

Heyendaalseweg 135, 6525AJ Nijmegen (The Netherlands)

E-mail:m.tessari@science.ru.nl

J.-M. Tyburn

Bruker BioSpin $\mathrm{GmbH}$

Silberstreifen, Rheinstetten (Germany)

Dr. J. G. Kempf

Bruker Biospin Corp.

Billerica, MA 01821 (USA)

(2) Supporting information and the ORCID identification number(s) for the author(s) of this article can be found under: https://doi.org/10.1002/anie.201703577.
However, each of these comes with further penalties in sensitivity and experiment time. Consequently, DOSY of dilute low-micromolar analytes is not feasible if relying only on traditional measures for NMR sensitivity. Herein, however, we demonstrate that the combination of DOSY with nuclear spin hyperpolarization brings the application limit down to low-micromolar solutes.

Among the various nuclear hyperpolarization techniques, dissolution $\mathrm{DNP}^{[6]}$ and $\mathrm{SABRE}^{[7]}$ have already been used for signal enhancement in the study of synthetic ${ }^{[8]}$ and natural mixtures. ${ }^{[9]}$ SABRE has the particular advantage that it can

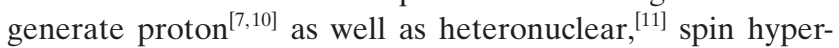
polarization in a few seconds in compounds that are able to transiently bind an iridium catalyst (Scheme 1). In addition to

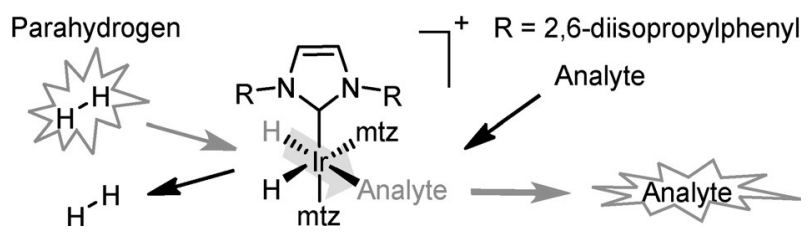

Scheme 1. SABRE hyperpolarization. Parahydrogen $\left(\mathrm{pH}_{2}\right)$, Ir-catalyst, cosubstrate (1-methyl-1,2,3-triazole, $\mathrm{mtz}$ ), and analytes are involved in a reversible binding equilibrium. During the lifetime of the complex, the spin order of $\mathrm{pH}_{2}$ is converted to nuclear hyperpolarization in analytes. ${ }^{[7]}$ Polarization transfer is conducted at low field outside the NMR magnet, after which the sample is inserted into the spectrometer for detection. An excess of $\mathrm{mtz}$ is needed for sub-millimolar SABRE to restore catalyst activity at low analyte concentrations. ${ }^{[13]}$

nitrogenous heteroaromatics, ${ }^{[7,8,9 a, b]}$ examples of sulfur heteroaromatic compounds, ${ }^{[10]}$ nitriles, ${ }^{[11 a]}$ Schiff bases ${ }^{[11 b]}$ and diazirines $^{[11 c]}$ have been reported. Several such SABREactive moieties appear in the structures of drugs, ${ }^{[11 \mathrm{~d}, 12]}$ odorants ${ }^{\left[{ }^{[b]}\right]}$ and metabolites, ${ }^{[9 a]}$ giving rise to an interest in devising new analytical approaches for their detection. Furthermore, although the original SABRE methods did not maintain the quantitative abilities of NMR spectroscopy, a general approach to analytical SABRE was recently developed and used for quantification of sub-micromolar analytes (Scheme 1). ${ }^{[13]}$

Figure 1 depicts the aromatic region of a single-scan SABRE spectrum of a mixture of six dilute analytes. The molecules 1-6 and similar analogues occur as low-micromolar concentration flavor components in food extracts, ${ }^{[14]}$ but spectral elucidation of their mixtures is complicated if based on 1D spectra alone. Herein, we overcome this challenge with a new method that combines SABRE with DOSY to resolve the signals of analytes 1-6 at low-micromolar concentrations. 


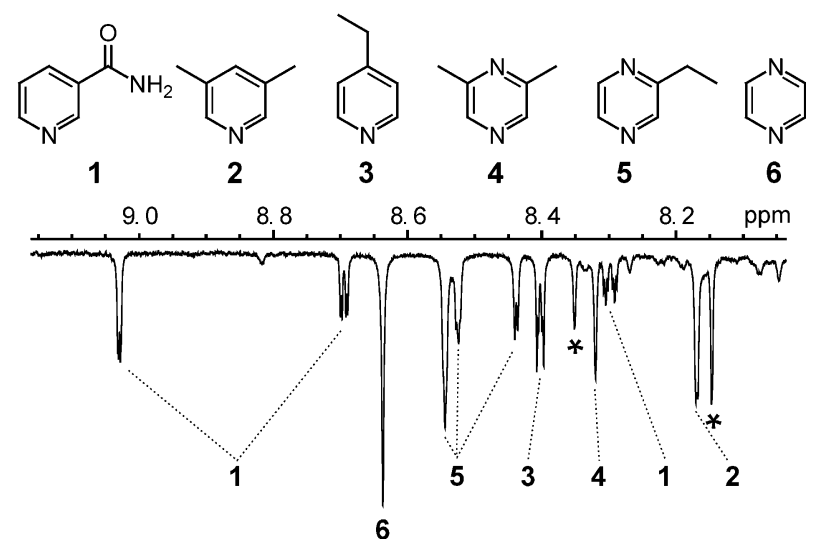

Figure 1. Region of interest of SABRE spectrum. Concentrations of analytes are $25 \mu \mathrm{M}(1), 10 \mu \mathrm{M}(2-5)$, and $5 \mu \mathrm{M}$ (6). Catalyst-mtz background signals are highlighted with $(*)$. Note that SABRE enhances each signal by a factor that is not directly related to analyte concentration. Full spectrum and thermal reference are available in the Supporting Information.

Single-scan diffusion NMR techniques are not applicable for this purpose, since these either sacrifice resolution for measurement time, ${ }^{[15]}$ have reduced sensitivity due to spatial encoding, ${ }^{[16]}$ or are not compatible with the $T_{1}$ relaxation rate of ${ }^{1} \mathrm{H}$ nuclei. ${ }^{[17]}$ Hence, SABRE-DOSY of low-micromolar analytes is necessarily a multi-scan experiment. Several groups have implemented specialized hardware for automatic sample transfer between low- and high-field in $p \mathrm{H}_{2}$ hyperpolarization experiments. ${ }^{[18]}$ In this work, we have employed the flow system described in Refs. [18b,19] (see Experimental Section) to control sample transfer between the hyperpolarization chamber and the NMR probe. As previously demonstrated, this system allows repeated SABRE experi- ments with a reproducibility within $2-5 \%,{ }^{[19]}$ sufficient for incorporating SABRE hyperpolarization into traditional 2D NMR pulse schemes.

Nevertheless, performing DOSY under stopped-flow conditions is a challenge, as convection generated by flow displacement and by associated temperature gradients can overshadow the thermal diffusion. Managing this convection is paramount, since convective effects on gradient-encoded NMR experiments cause anomalies in signal amplitude and phase. ${ }^{[20]}$ Herein, the issue was mitigated by a careful optimization of experimental parameters, such as matched temperatures of sample with that of the NMR probe and judicious insertion of $5 \mathrm{~s}$ stabilization delays to dampen the remaining convection (see Experimental Section).

Under these conditions, we were able to record wellresolved DOSY spectra of a mixture of analytes 1-6 in the concentration range of $5-25 \mu \mathrm{M}$ in $35 \mathrm{~min}$ (Figure 2, left panel). SABRE provides 98- to 232-fold signal enhancements for these analytes after the $5 \mathrm{~s}$ delay, enabling DOSY at concentrations two orders of magnitude lower than would be feasible from thermal NMR signals in a similar time frame. To achieve the same SNR by signal averaging thermal signals, a 10000 -fold $\left(=\left(10^{2}\right)^{2}\right)$ increase in number of scans would be required. For the sake of comparison, a non-hyperpolarized regular DOSY spectrum of the same mixture of analytes at circa 1000 -fold higher concentration is also displayed in Figure 2 (right panel). Diffusion coefficients are identical in the two DOSY spectra, demonstrating that both sample shuttling and analyte interaction with the SABRE catalyst have negligible influence on the results. This may seem surprising, since coordination to transition metals has been previously used to modify diffusion coefficients in DOSY. ${ }^{[21]}$ However, the dissociation of the catalyst complex (Scheme 1) is in the present case extremely slow, causing the interference

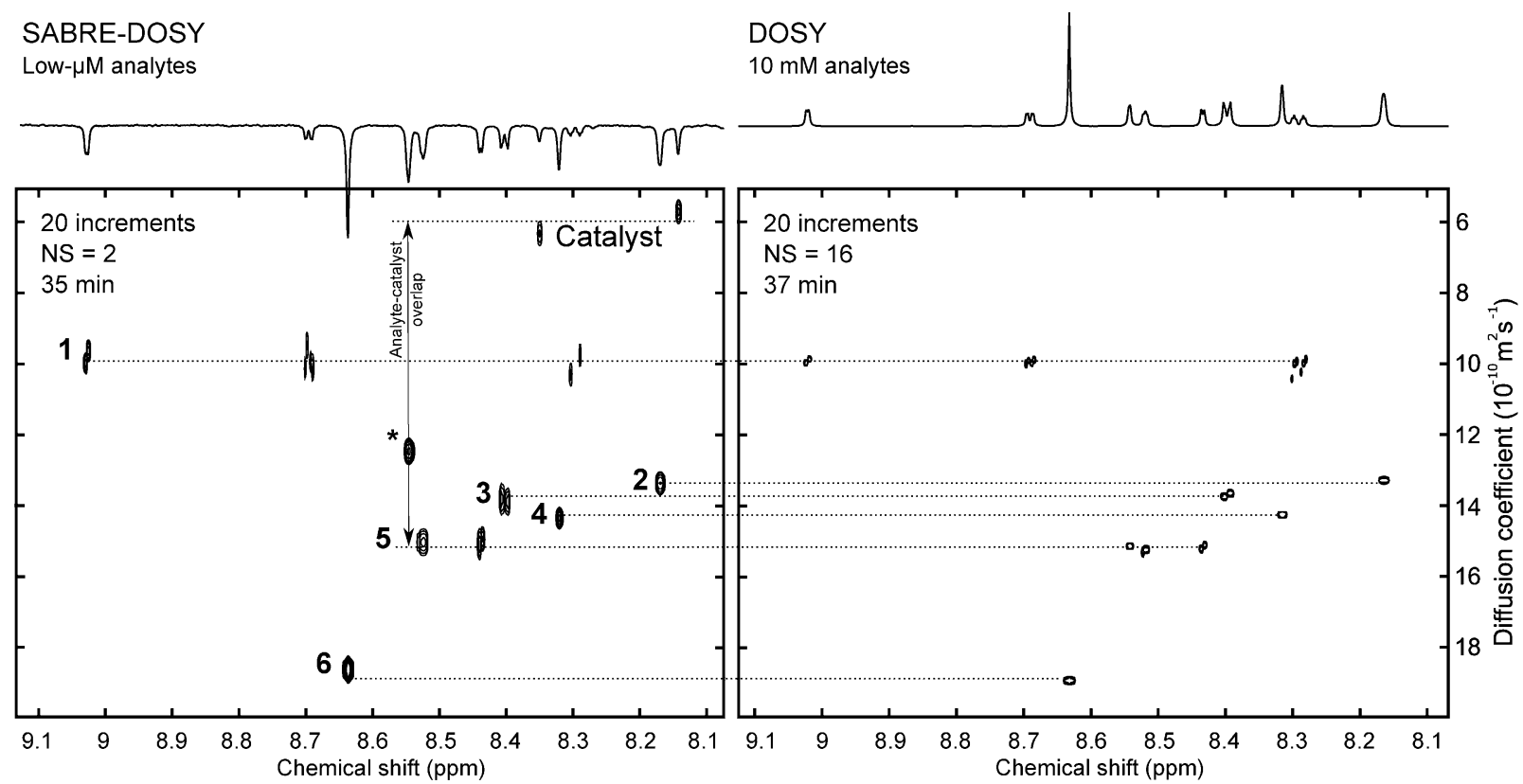

Figure 2. $2 \mathrm{D}$ plots of low-micromolar SABRE-DOSY and $10 \mathrm{~mm}$ DOSY experiments in $\left[\mathrm{D}_{4}\right] \mathrm{MeOH}$. Experimental details are available in the Supporting Information. 
between the diffusion of analytes in their free and catalystbound forms to be small. As previously reported, ${ }^{[22]}$ this is due to the 1-methyl-1,2,3-triazole cosubstrate that dramatically slows down analyte dissociation in NHC-iridium SABRE complexes; dissociation rates lower than $1 \mathrm{~s}^{-1}$ have been determined for complexes analogous to the one used herein. The combination of the slow analyte exchange and a short diffusion delay $(50 \mathrm{~ms})$ cause systematic deviations on the determined diffusion coefficients to be below detection. ${ }^{[23]}$

Note that the regular DOSY displays a much smaller linewidth in the indirect (diffusion) dimension due to the higher signal-to-noise ratio achieved at high concentrations. A similar resolution might be achieved by SABRE-DOSY at low concentrations without any penalty in experimental time by simply employing fully enriched $p \mathrm{H}_{2}$ instead of the circa $50 \%$ enrichment used herein, which would provide a nearly three-fold additional signal increase.

All analytes in the low-micromolar mixture are resolved in the SABRE-DOSY plot of Figure 2. That enables assessment of the number of analytes and correlation of distinct peaks from a given analyte. Two of the signals can be dismissed from as not being from the analyte pool, since they also appear in the SABRE spectrum of the neat catalyst-mtz solution (Supporting Information, Figure S4). Among the analytes, signals of the slowest diffusing member $\mathbf{1}$ were easily correlated, while the lightest analyte $\mathbf{6}$ is clearly resolved as the fastest diffusing component. Furthermore, the two pairs of isomeric alkyl pyridines 2-3 and pyrazines 4-5 are clearly resolved. This is an impressive result, considering that diffusion coefficients are expected to correlate to the size of analytes and this set varies by no more than one atomic mass unit and comprises the same basic molecular shape. However, we have recently demonstrated that $\left[\mathrm{D}_{4}\right] \mathrm{MeOH}$ enhances resolution in the diffusion of nitrogenous aromatics, including the differentiation of isomers. ${ }^{[24]}$ Finally, a remaining problem is that one of the peaks from $\mathbf{5}$ (asterisk in Figure 2) overlaps with a catalyst-mtz signal (Figure S4) and does not properly correlate with other resonances from 5. Resolving such overlap is a well-recognized issue in DOSY that could potentially be solved by more advanced data processing techniques. $^{[25]}$

In summary, we demonstrate a method to greatly lower the concentration floor for DOSY. This was achieved in the face of flow and mixing steps necessitated for SABRE hyperpolarization. We acknowledge that the approach is limited to analytes that can reversibly bind the iridium-based SABRE catalyst, however, key analytical applications within this realm have been demonstrated ${ }^{[9 a-b]}$ and are poised to grow. Without SABRE and its corresponding $(100+)$-fold sensitivity gains, DOSY analysis of low-micromolar mixtures would not be feasible. Furthermore, additional gains will be straightforward to achieve in this framework by moving to $>90 \% \mathrm{pH}_{2}$. Combining the present approach with recent advances in single-scan DOSY ${ }^{[16]}$ could allow $<1$ min measurement times, but the spatial encoding employed in such experiments would reduce sensitivity with a corresponding tradeoff on the detection limit of SABRE-DOSY. The resolution and sensitivity of the method herein provide an important new piece in the toolbox for mixture analysis by
NMR spectroscopy and take steps forward in the everexpanding fields of DOSY and nuclear hyperpolarization.

\section{Experimental Section}

Managing convection: Experiments were carried out in a SABRE polarizer (Figure 3). Mixing of the sample while the flow cell is filled helps to eliminate temperature gradients across sample volume if the

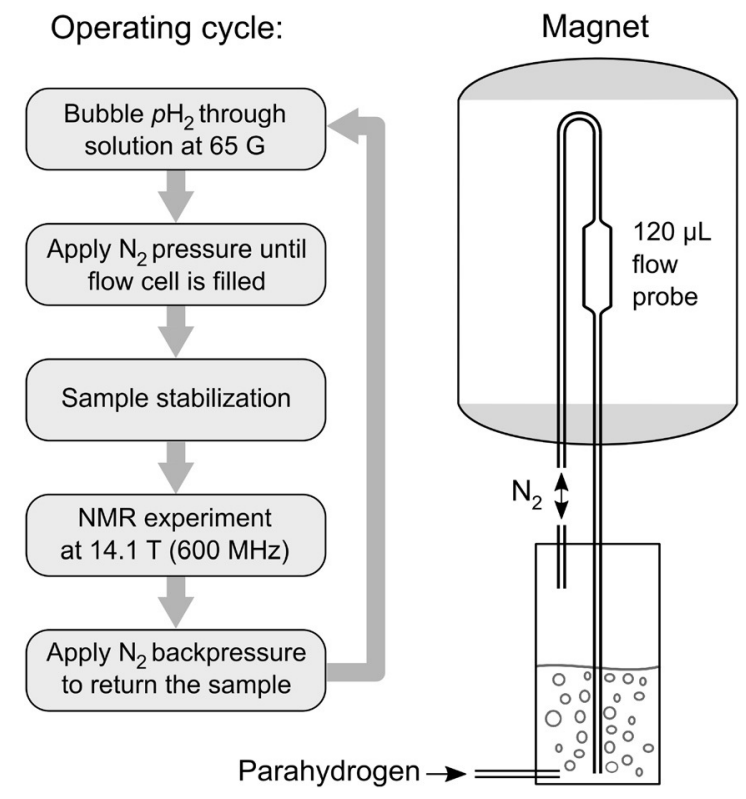

Figure 3. Schematic of SABRE polarizer. The system provides automated flow control and handles mixing with $\mathrm{pH}_{2}$ in a controlled lowfield environment appropriate to SABRE (details in the Supporting Information).

sample and flow probe temperatures are matched (Supporting Information, Figure S5). Residual convection was evaluated with the asymmetric double stimulated echo sequence ${ }^{[26]}$ that separates diffusion from convection (Figure S6). Convection dampens to below detection in $5 \mathrm{~s}$, suggesting that DOSY is possible after a $5 \mathrm{~s}$ delay. This is in accordance with earlier reports on stop flow experiments in flow probes, in which convection dampened quickly to levels that had little effect on gradient-encoded experiments. ${ }^{[27]}$ Considering that the effective $T_{1}$ relaxation time ${ }^{[28]}$ of protons in analytes $\mathbf{1}-\mathbf{6}$ is $10-12 \mathrm{~s}$, the relaxational loss of signal during the $5 \mathrm{~s}$ delay is $30-40 \%$.

SABRE-DOSY experiment: The sample consisted of 6 lowmicromolar analytes, $0.5 \mathrm{~mm}$ of catalyst, and $15 \mathrm{~mm}$ of cosubstrate in $3.5 \mathrm{~mL}$ of $\left[\mathrm{D}_{4}\right] \mathrm{MeOH}$. Operation of the SABRE polarizer is described in the Supporting Information. Spectra were recorded with the Doneshot sequence, using $1.2 \mathrm{~ms}$ half-sine gradient pulses, $50 \mathrm{~ms}$ diffusion time, 20 gradient increments, and two scans per increment. Further details can be found in the Supporting Information.

\section{Acknowledgements}

We acknowledge financial support from the European Union and the provinces of Gelderland and Overijssel through the EFRO Ultrasense NMR project. We acknowledge financial support from the Dutch Ministry of Education, Culture and Science (Gravitation program 024.001.035). 


\section{Conflict of interest}

The authors declare no conflict of interest.

Keywords: DOSY · hyperpolarization - NMR spectroscopy parahydrogen . SABRE

How to cite: Angew. Chem. Int. Ed. 2017, 56, 9174-9177 Angew. Chem. 2017, 129, 9302-9305

[1] C. S. Johnson, Prog. Nucl. Magn. Reson. Spectrosc. 1999, 34, $203-256$.

[2] M. G. S. Vieira, N. V. Gramosa, N. M. P. S. Ricardo, G. A Morris, R. W. Adams, M. Nilsson, RSC Adv. 2014, 4, 4202942034.

[3] G. Pagès, A. Bonny, V. Gilard, M. Malet-Martino, Anal. Chem. 2016, 88, 3304-3309.

[4] M. Nilsson, G. A. Morris, J. Magn. Reson. 2005, 177, 203-211.

[5] M. Foroozandeh, L. Castañar, L. G. Martins, D. Sinnaeve, G. D. Poggetto, C. F. Tormena, R. W. Adams, G. A. Morris, M. Nilsson, Angew. Chem. Int. Ed. 2016, 55, 15579-15582; Angew. Chem. 2016, 128, 15808-15811.

[6] J. H. Ardenkjaer-Larsen, B. Fridlund, A. Gram, G. Hansson, L. Hansson, M. H. Lerche, R. Servin, M. Thaning, K. Golman, Proc. Natl. Acad. Sci. USA 2003, 100, 10158-10163.

[7] R. W. Adams, J. A. Aguilar, K. D. Atkinson, M. J. Cowley, P. I. P. Elliott, S. B. Duckett, G. G. R. Green, I. G. Khazal, J. LópezSerrano, D. C. Williamson, Science 2009, 323, 1708-1711.

[8] N. Eshuis, B. J. A. van Weerdenburg, M. C. Feiters, F. P. J. T. Rutjes, S. S. Wijmenga, M. Tessari, Angew. Chem. Int. Ed. 2015 54, 1481-1484; Angew. Chem. 2015, 127, 1501-1504.

[9] a) I. Reile, N. Eshuis, N. K. J. Hermkens, B. J. A. van Weerdenburg, M. C. Feiters, F. P. J. T. Rutjes, M. Tessari, Analyst 2016, 141, 4001-4005; b) N. K. J. Hermkens, N. Eshuis, B. J. A van Weerdenburg, M. C. Feiters, F. P. J. T. Rutjes, S. S. Wijmenga, M. Tessari, Anal. Chem. 2016, 88, 3406-3412; c) J.-N Dumez, J. Milani, B. Vuichoud, A. Bornet, J. Lalande-Martin, I. Tea, M. Yon, M. Maucourt, C. Deborde, A. Moing, et al., Analyst 2015, 140, 5860-5863.

[10] R. V. Shchepin, D. A. Barskiy, A. M. Coffey, B. M. Goodson, E. Y. Chekmenev, ChemistrySelect 2016, 1, 2552-2555.

[11] a) R. E. Mewis, R. A. Green, M. C. R. Cockett, M. J. Cowley, S. B. Duckett, G. G. R. Green, R. O. John, P. J. Rayner, D. C Williamson, J. Phys. Chem. B 2015, 119, 1416-1424; b) A. W. J. Logan, T. Theis, J. F. P. Colell, W. S. Warren, S. J. Malcolmson, Chem. Eur. J. 2016, 22, 10777-10781; c) T. Theis, G. X. Ortiz, A. W. J. Logan, K. E. Claytor, Y. Feng, W. P. Huhn, V. Blum, S. J. Malcolmson, E. Y. Chekmenev, Q. Wang, W. S. Warren, Sci. Adv. 2016, 2, e1501438; d) D. A. Barskiy, R. V. Shchepin, A. M. Coffey, T. Theis, W. S. Warren, B. M. Goodson, E. Y. Chekmenev, J. Am. Chem. Soc. 2016, 138, 8080-8083; e) M. J. Burns, P. J. Rayner, G. G. R. Green, L. A. R. Highton, R. E. Mewis, S. B. Duckett, J. Phys. Chem. B 2015, 119, 5020-5027; f) A. M. Olaru, A. Burt, P. J. Rayner, S. J. Hart, A. C. Whitwood, G. G. R. Green, S. B. Duckett, Chem. Commun. 2016, 52, 14482-14485.
[12] H. Zeng, J. Xu, J. Gillen, M. T. McMahon, D. Artemov, J.-M. Tyburn, J. A. B. Lohman, R. E. Mewis, K. D. Atkinson, G. G. R. Green, et al., J. Magn. Reson. 2013, 237, 73-78.

[13] N. Eshuis, N. Hermkens, B. J. A. van Weerdenburg, M. C. Feiters, F. P. J. T. Rutjes, S. S. Wijmenga, M. Tessari, J. Am. Chem. Soc. 2014, 136, 2695-2698.

[14] S. Pickard, I. Becker, K.-H. Merz, E. Richling, J. Agric. Food Chem. 2013, 61, 6274-6281.

[15] J. Mitchell, M. L. Johns, Concepts Magn. Reson. Part A 2009, $34 A, 1-15$.

[16] L. Guduff, I. Kuprov, C. van Heijenoort, J. Dumez, Chem. Commun. 2017, 53, 701-704.

[17] B. L. Koelsch, K. R. Keshari, T. H. Peeters, P. E. Z. Larson, D. M. Wilson, J. Kurhanewicz, Analyst 2013, 138, 1011-1014.

[18] a) J. B. Hövener, E. Y. Chekmenev, K. C. Harris, W. H. Perman, L. W. Robertson, B. D. Ross, P. Bhattacharya, MAGMA 2009, 22, 111-121; b) M. J. Cowley, R. W. Adams, K. D. Atkinson, M. C. R. Cockett, S. B. Duckett, G. G. R. Green, J. A. B. Lohman, R. Kerssebaum, D. Kilgour, R. E. Mewis, J. Am. Chem. Soc. 2011, 133, 6134-6137; c) A. S. Kiryutin, K. L. Ivanov, A. V. Yurkovskaya, R. Kaptein, H.-M. Vieth, Z. Phys. Chem. 2012, 226, 1343-1362; d) A. S. Kiryutin, A. N. Pravdivtsev, K. L. Ivanov, Y. A. Grishin, H. M. Vieth, A. V. Yurkovskaya, J. Magn. Reson. 2016, 263, 79-91.

[19] L. S. Lloyd, R. W. Adams, M. Bernstein, S. Coombes, S. B. Duckett, G. G. R. Green, R. J. Lewis, R. E. Mewis, C. J. Sleigh, J. Am. Chem. Soc. 2012, 134, 12904-12907.

[20] I. Swan, M. Reid, P. W. A. Howe, M. A. Connell, M. Nilsson, M. A. Moore, G. A. Morris, J. Magn. Reson. 2015, 252, 120-129.

[21] A. K. Rogerson, J. A. Aguilar, M. Nilsson, G. A. Morris, Chem. Commun. 2011, 47, 7063-7064.

[22] N. K. J. Hermkens, M. C. Feiters, F. P. J. T. Rutjes, S. S. Wijmenga, M. Tessari, J. Magn. Reson. 2017, 276, 122-127.

[23] E. J. Cabrita, S. Berger, Magn. Reson. Chem. 2002, 40, S122S127.

[24] I. Reile, R. L. E. G. Aspers, M. C. Feiters, F. P. J. T. Rutjes, M. Tessari, Magn. Reson. Chem. 2017, https://doi.org/10.1002/mrc. 4587.

[25] I. Toumi, B. Torrésani, S. Caldarelli, Anal. Chem. 2013, 85, $11344-11351$.

[26] N. M. Loening, J. Keeler, J. Magn. Reson. 1999, 139, 334-341.

[27] a) H.-Y. Chen, C. Hilty, ChemPhysChem 2015, 16, 2646-2652; b) S. Ahola, V. V. Zhivonitko, O. Mankinen, G. Zhang, A. M. Kantola, H.-Y. Chen, C. Hilty, I. V. Koptyug, V.-V. Telkki, Nat. Commun. 2015, 6, 8363.

[28] Effective $T_{1}$ is the weighted average of the relaxation of the interchanging free and bound analytes (due to exchange of ligands in the complex of Scheme 1).

Manuscript received: April 6, 2017

Revised manuscript received: May 25, 2017

Accepted manuscript online: June 7, 2017

Version of record online: June 28, 2017 